\title{
Septic cavernous sinus thrombosis with infectious arteritis of the internal carotid artery
}

\author{
Hwa Reung Lee, Hye Weon Kim, Joong Hyun Park, Sang Won Han
}

Department of Neurology, Sanggye Paik Hospital, Inje University College of Medicine, Seoul, Republic of Korea

\section{Correspondence to}

Professor Sang Won Han, swhan@paik.ac.kr

Accepted 14 November 2015

CrossMark

\begin{tabular}{l}
\hline To cite: Lee HR, Kim HW, \\
Park JH, et al. BMJ Case \\
Rep Published online: \\
[please include Day Month \\
Year] doi:10.1136/bcr-2015- \\
213314 \\
\hline
\end{tabular}

\section{DESCRIPTION}

Septic cavernous sinus thrombosis (CST) is thrombophlebitis in the cavernous sinus. It is an unusual complication of paranasal sinusitis, otitis media and, less often, pharyngitis and dental infection, affecting the anatomic structures running in the cavernous sinus. ${ }^{1-3}$ Ophthalmoplaegia may be the presenting symptom of cavernous sinus thrombosis. Impaired extraocular muscle motility is seen, usually starting with a lateral gaze. ${ }^{3}$ Contrary to nervous system structures, however, the internal carotid artery (ICA) is rarely involved.

A 53-year-old woman without contributory medical history was admitted to our hospital with a high fever, left-sided headache and swelling of the left eye. Two days before admission, she developed hot flash-like symptoms and severe headache. Painful eye swelling developed on the left side 2 days later, and she visited our hospital. On physical examination, her temperature was $40.5{ }^{\circ} \mathrm{C}$, pulse was $86 \mathrm{bpm}$ and blood pressure was $142 /$ $82 \mathrm{~mm} \mathrm{Hg}$. She was alert and oriented. Her left eyelid presented with marked swelling, redness and ptosis accompanied by haemorrhagic conjunctival hyperaemia and exophthalmos. When her eye was passively opened, the left eye was adducted and failed to abduct with examination, which suggested left abducens nerve palsy. The direct pupillary light reflex, visual acuity, intraocular pressure and ophthalmoscopic findings were normal. Orbital CT and MRI showed chemosis, extraocular muscular thickening and ocular proptosis on the left side, while paranasal sinusitis was absent (figure 1A, B). Brain MR angiography (MRA) demonstrated narrowing of the left ICA at the intracavernous portion (figure 1C). The diagnosis of a septic CST was performed and the patient's symptoms improved with intravenous antibiotic therapy. She was discharged after 2 weeks of intravenous antibiotic therapy, without any symptoms. Follow-up brain CT angiography after
7 months showed that the visualised narrowing of the left intracavernous ICA on the previous MRA had almost disappeared (figure 1D).

\section{Learning points}

Septic cavernous sinus thrombosis (CST) is thrombophlebitis in the cavernous sinus.

- It is an unusual complication of paranasal sinusitis, otitis media and, less often, pharyngitis and dental infection.

- Ophthalmoplaegia may be the presenting symptom of a cavernous sinus thrombosis. Impaired extraocular muscle motility is seen, usually starting with a lateral gaze.

- A clinical course with infectious arteritis of the internal carotid artery as major complication of septic CST is rare and requires prompt treatment.

Contributors HRL, HWK and JHP conceived and wrote this article, and SWH supervised it.

Competing interests None declared.

Patient consent Obtained.

Provenance and peer review Not commissioned; externally peer reviewed.

\section{REFERENCES}

1 Suntrup S, Kemmling A, Dziewas R, et al. Septic cavernous sinus thrombosis complicated by occlusion of the internal carotid artery and multiple embolic strokes after surgery of an anorectal abscess: a clinical chameleon. Neurologist 2012;18:310-12.

2 Hoshino C, Satoh N, Sugawara S, et al. Septic cavernous sinus thrombosis complicated by narrowing of the internal carotid artery, subarachnoid abscess and multiple pulmonary septic emboli. Intern Med 2007;46:317-23.

3 Duong DK, Leo MM, Mitchell EL. Neuro-ophthalmology. Emerg Med Clin North Am 2008;26:137-80, vii.

\footnotetext{
Copyright 2015 BMJ Publishing Group. All rights reserved. For permission to reuse any of this content visit http://group.bmj.com/group/rights-licensing/permissions.

BMJ Case Report Fellows may re-use this article for personal use and teaching without any further permission.

Become a Fellow of BMJ Case Reports today and you can:

- Submit as many cases as you like

- Enjoy fast sympathetic peer review and rapid publication of accepted articles

- Access all the published articles

- Re-use any of the published material for personal use and teaching without further permission

For information on Institutional Fellowships contact consortiasales@bmjgroup.com

Visit casereports.bmj.com for more articles like this and to become a Fellow
} 
Figure 1 Orbital CT and MRI showing chemosis, extraocular muscular thickening and ocular proptosis on the left side (A and B). (C) Brain MRA demonstrating narrowing of the left ICA at the intracavernous portion. (D) Follow-up brain CT angiography revealing that visualised narrowing of the left intracavernous ICA on the previous MRA had almost disappeared. ICA, internal carotid artery; MRA, MR angiography.

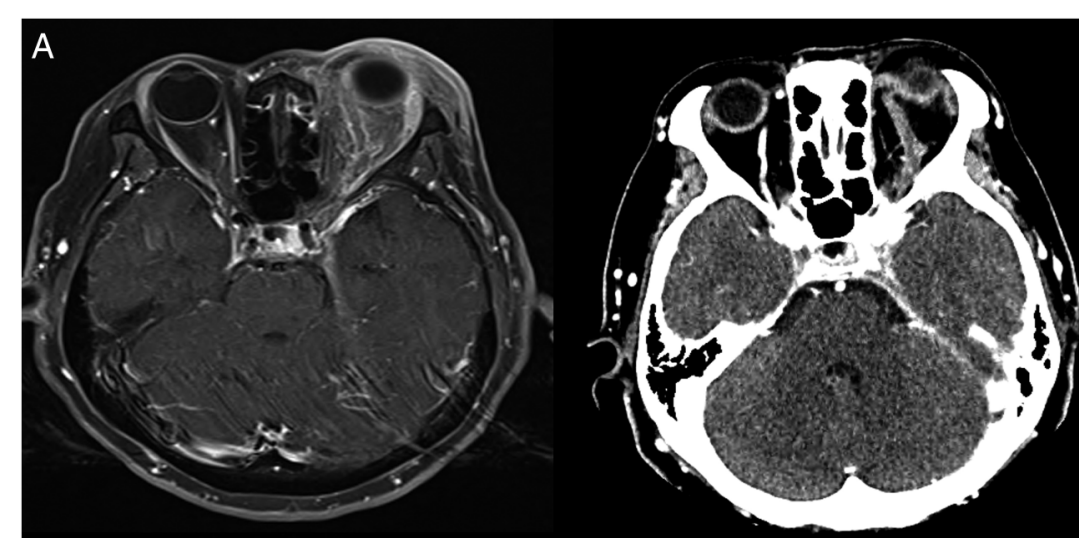

B
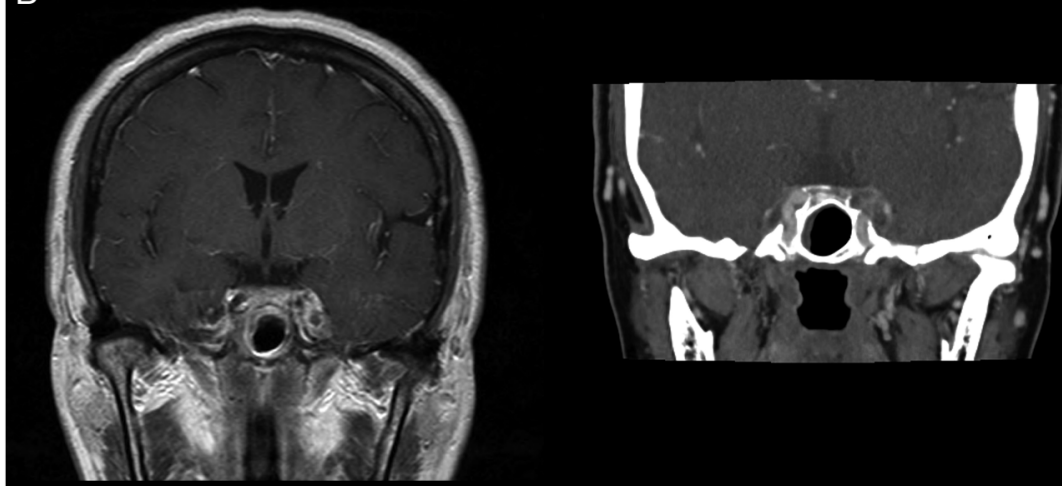

C

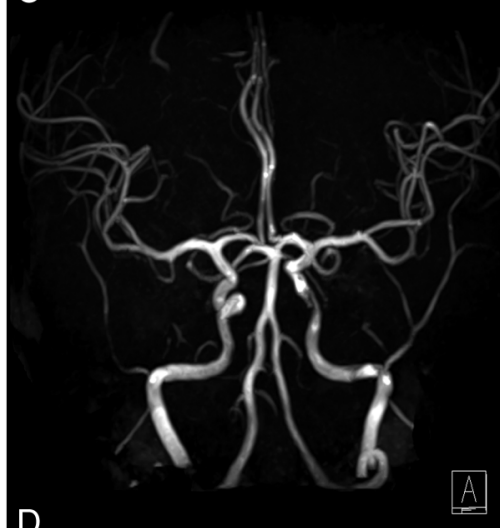

D

H

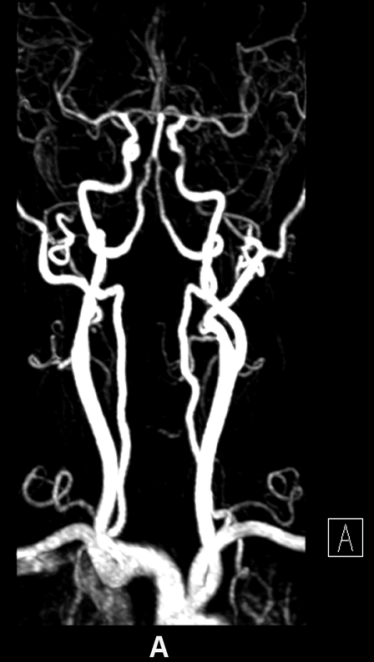

A 